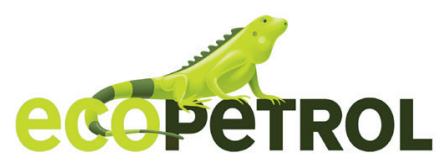

ctyf@ecopetrol.com.co

\title{
PHOTOCATALYTIC DEGRADATION OF HYDROCARBONS PRESENT IN WATER, USING Fe (III) MODIFIED $\mathrm{TiO}_{2}$.
}

\section{DEGRADACIÓN FOTOCATALÍTICA DE HIDROCARBUROS PRESENTES EN AGUA, USANDO $\mathrm{TiO}_{2}$ MODIFICADO CON Fe (III).}

Velosa- Alfonso, Paula-Catalina ${ }^{*} ;$ Loaiza- Carreño, Andrés-Felipe ${ }^{b} ;$ Quiñones- Segura, Cesar- Augusto ${ }^{a}$

\section{ABSTRACT}

This research work focused on the degradation of total hydrocarbons in synthetic water mixtures and in samples obtained from the inflow of a skimmer (production water) by means of heterogeneous photocatalysis. Titanium dioxide $\left(\mathrm{TiO}_{2}\right)$ was used, modified with iron oxide (III) as photocatalyst, supported on polymethyl methacrylate plates, arranged in two reactors with volumetric capacities of $15.0 \mathrm{ml}$ and $1.0 \mathrm{l}$. The degradation process was studied using two analysis methods: Photometric detection and gravimetric partition. Degradation percentages of $91.2 \%$ and $98 \%$ were obtained in field samples and synthetic mixtures respectively, with $4 \mathrm{~h}$ times; this allows for assessment of this technique's impact on the treatment of produced water in the oil industry, seeking for an alternative to the methods for treating water contaminated with hydrocarbons.

\section{RESUMEN}

En esta investigación se llevó a cabo la degradación de hidrocarburos totales en mezclas sintéticas de agua y en muestras obtenidas del flujo de entrada de un skimmer (agua de producción), por medio de fotocatálisis heterogénea. Se usó dióxido de titanio $\left(\mathrm{TiO}_{2}\right)$ modificado con óxido de hierro (III) como fotocatalizador, soportado en láminas de polimetilmetacrilato, dispuestas en dos reactores con capacidades volumétricas de 15,0 $\mathrm{ml}$ y 1,0 l. El proceso de degradación fue estudiado mediante dos métodos de análisis: Detección fotométrica y partición gravimétrica. Se obtuvieron porcentajes de degradación de $91.2 \%$ y $98 \%$ en muestras de campo y mezclas sintéticas respectivamente, en tiempos de $4 \mathrm{~h}$; los cuales permiten evaluar el impacto de esta técnica en el tratamiento de agua de producción de la industria petrolera, buscando ser una alternativa a los métodos de tratamiento de aguas contaminadas con hidrocarburos.
Production water | Modified Titanium Dioxide |

Photo-degradation I Hydrocarbon.

Aguas de producción | Dióxido de Titanio modificado |

Fotodegradación | Hidrocarburos. a Fundación Universidad América, Chemical Engineering Department, Avda Circunvalar No. 20-53, Bogotá DC, Colombia. - Tecno Academia Nodo Cazuca, SENA, Autopista Sur Transversal 7 № 8 - 40, Soacha, Colombia. *email: paulac_gc@hotmail.com 


\section{INTRODUCTION}

Currently, numerous water sources throughout the country are highly contaminated due to various industrial activities, including the extraction of crude oil [1]. According to Ecopetrol SA [2], for each barrel of crude extracted, an average of four barrels of contaminated water (production water) is generated, a proportion that increases along with the maturity of the well [3].

The contaminated water resulting from the extraction processes and water used for reinjection must be treated before being discharged into natural sources, reinjected, or used in agricultural activities [4]. Its composition may vary depending on the reservoir, but it is estimated that this production water is composed of oil (500 to 5000 ppm), sulfates, bicarbonates, cyanide, carbon dioxide, and heavy metals such as cadmium, arsenic, chromium, lead, mercury, vanadium and zinc. Such pollutants change the organoleptic characteristics of water, as the contact of their components with the ecosystem causes negative impacts on the environment; given that their high salinity and the presence of heavy metals are potentially toxic to the fauna present in water bodies [5].

Conventional treatment technologies produce chemically stable emulsions that are difficult to break [6] and non-conventional technologies, such as osmosis, electro dialysis, exchange for ion removal (OR, IOR), among others, require high investment [7] .

This is the scenario where the Advanced Oxidation Processes (AOPs) become relevant as they involve the generation of hydroxyl radicals $(\mathrm{OH} \cdot)$, very potent and non-selective oxidizing agents, which chemically modify or mineralize organic pollutants and inorganic substances present in water bodies and samples of all types [8] [10]. The $(\mathrm{OH} \cdot)$ are generated from physical-chemical processes involving chemical agents such as ozone [11], hydrogen peroxide [12], $\mathrm{Fe}^{2+}$ (along with hydrogen peroxide in the Fenton reagent) [13] and physicochemical processes such as the electronic excitation of semiconductor materials (excitation of titanium dioxide using UV radiation) [14].

The heterogeneous photocatalysis is an advanced oxidation technology, which consists of using a semiconductor, commonly titanium dioxide $\left(\mathrm{TiO}_{2}\right)$, to photocatalyze chemical reactions of organic and inorganic substances and obtain lower toxicity substances or carbon dioxide [15]. Through the process, the incident radiation excites an electron from the valence band to the conduction band, generating an electron-hole pair, charge carriers, which when approaching the semiconductor surface can generate oxidationreduction reactions with the adsorbed species [16]. The $\mathrm{TiO}_{2}$ is highly available, innocuous, inert, economically and chemically stable, and requires UV radiation (wavelength around $340 \mathrm{~nm}$ ) to generate hole electron pairs, which directly or indirectly are responsible for the oxidation-reduction degradation reactions [17].

In this research, the photocatalytic degradation of hydrocarbons present in synthetic water mixtures prepared in the laboratory was performed from a known crude oil and in samples collected from the skimmer inflow (production water).

$\mathrm{TiO}_{2}$ modified with iron (III) oxide is used in order to sensitize the $\mathrm{TiO}_{2}$ and thus use the visible radiation wavelength $(400-700 \mathrm{~nm})$ to perform the degradation, considering its industrial application by using the solar radiation high exposure in oil exploration areas. The percentage of total hydrocarbon degradation (HTP's) was estimated by measuring the absorbency of the samples as a function of the degradation time: Photometric detection and contracted services for quantification of HTP's mg / l (total hydrocarbons of petroleum origin) using the gravimetric partition method in the laboratories of Prodycon SA [18]

\section{EXPERIMENTAL DEVELOPMENT}

Semiconductor $\mathrm{TiO}_{2}$ Degussa P-25 modified with iron (III), by means of the cyclic chemisorption-calcination method with iron (III) acetylacetonate [19], a dry impregnation is carried out with the iron precursor that was supported on polymethyl methacrylate plates by an adhesion method [20]. It is calcined for 2 hours at a temperature of $500^{\circ} \mathrm{C}$. Then, the subsequent characterizations showed that the precursor decomposed and formed the iron oxide; regarding the $\mathrm{X}$-ray diffraction characterization, it was carried out to ensure that the percentages of anatase and rutile corresponded to $80 \%$ and $20 \%$ respectively, according to the data reported in the technical data sheet of the Degussa P-25; in terms of morphological characterization, it was carried out in previous works by means of scanning electron microscopy (SEM) using the JEOL NeoScope JCM equipment 5000, observing parameters such as homogeneity, roughness and a particle size of radii similar to 25 $\mathrm{nm}$ and agglomerates of some particles ranging between $200 \mathrm{~nm}$ and $300 \mathrm{~nm}$.

The adherence of the photocatalyst to the films was evaluated by mass difference, before and after immersing, the plates in water for $72 \mathrm{~h}$ and losses of less than 10\% were obtained on average, a minimum percentage that allows the use and disposal of the plates in the reactors.

Three plates were arranged per reactor in parallel configuration, in cylindrical amber glass reactors with $1.0 \mathrm{l}$ and $15.0 \mathrm{ml}$ capacity, and lighting systems with the following characteristics were installed:
Table 1. Characteristics of the lighting system.

\begin{tabular}{|c|c|}
\hline Parameter & Value \\
\hline Radiation source & 3W LEDs \\
\hline Voltage & $3.0-4.0 \mathrm{~V} \mathrm{DC}$ \\
\hline Current & $700 \mathrm{~mA}$ \\
\hline Luminous flux & $230-240 \mathrm{LM}$ \\
\hline Vision angle & $120^{\circ}$ \\
\hline Color temperature & $5000-6000 \mathrm{~K}$ \\
\hline
\end{tabular}

In addition to air supply with an electric air pump, with $3 \mathrm{~W}$ power and $3 \mathrm{~L} / \mathrm{min} 20 \mathrm{kPa}$ flow. AC Power $110 \mathrm{~V} / 50 \mathrm{~Hz}$ and dimensions: $7.5 \times 4.6 \times 3.7 \mathrm{~cm}$, necessary for the photocatalytic process inside the reactors [17].

Synthetic water mixtures were prepared using API crude: 23.5 (campomax) and distilled water. The final concentrations are observed in Table 2.

The field sample was obtained from the inflow to a skimmer, from a plant located in the eastern plains region of Colombia. The initial concentration of total hydrocarbons in the sample was $145.9 \mathrm{mg} /$ $\mathrm{L}$, according to the TPH method (gravimetric partition) carried out by Prodycon SA. 
Table 2. Concentrations of synthetic samples (MSX) used in the evaluation of the total hydrocarbon degradation capacity of the reactors used.

\begin{tabular}{|c|c|}
\hline Sample & Concentration $(\mathrm{ppm})$ \\
\hline MS2 & 200 \\
\hline MS4 & 400 \\
\hline MS6 & 600 \\
MS8 & 800 \\
\hline MS10 & 1000 \\
\hline
\end{tabular}

The hydrocarbon degradation process was evaluated using two techniques. The turbidimetric technique was developed using a UVvis spectrophotometer - Ocean Optics, at 400 nm (experimentally selected based on the R 2 factor, from a sweep of calibration curves from 350 to $650 \mathrm{~nm}$ every $50 \mathrm{~nm}$ ). The total hydrocarbon analysis was carried out using the gravimetric partition technique, which consists of making successive extractions and the resulting organic fractions (containing the total hydrocarbons) are rigorously dried and their mass determined [21],[22].

The collection and preservation of water samples from the input flow to the skimmer required adjusting the $\mathrm{pH}$ of the samples with hydrochloric acid to $\mathrm{pH}$ below 2 . All samples subjected to solvent extraction for gravimetric tests remained refrigerated between ( 0 $4)^{\circ} \mathrm{C}$ from the time of field collection. All samples were analyzed within 28 days after being collected, as set out in the procedure [23].

\section{RESULTS}

Figure 1 illustrates the hydrocarbon degradation experiments, present in the samples mentioned in Table 2, using a $15.0 \mathrm{~mL}$ reactor. The concentrations were determined by turbidimetry (wavelength = $400 \mathrm{~nm}$ ). In general, it is observed that the photocatalytic activity is independent of the hydrocarbon concentration in the range of studied concentrations (200 - 1000 ppm). The degradation percentages specified in the figures correspond to a degradation time of 210 min. However, the concentration remains relatively constant after $100 \mathrm{~min}$.

Thanks to previously developed investigations, it is known that the percentages presented of adsorption (before photocatalysis) in the absence of radiation can be considered negligible, since the curves remain stable and their change over time is not considerable.

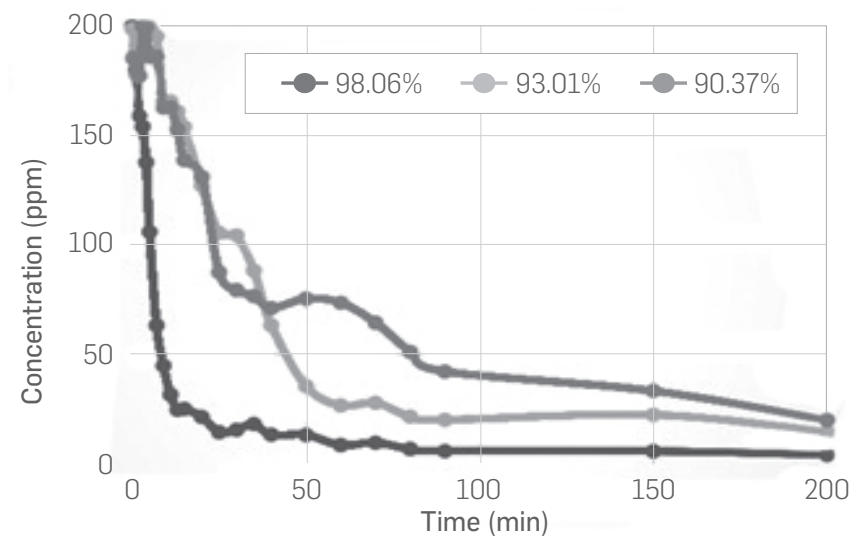

(a)

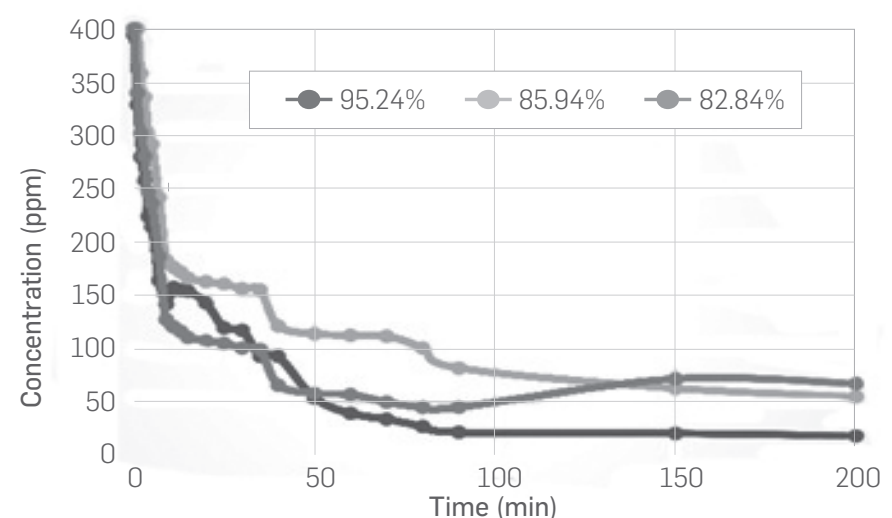

(b)



(c)

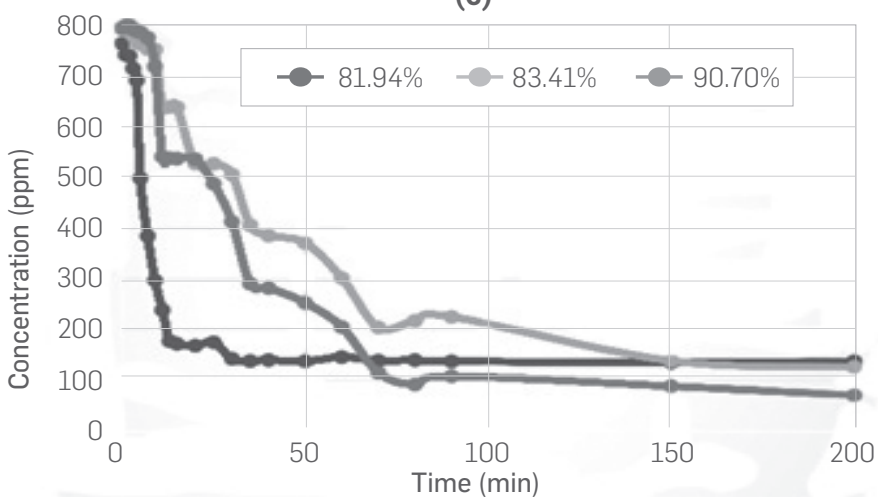

(d)

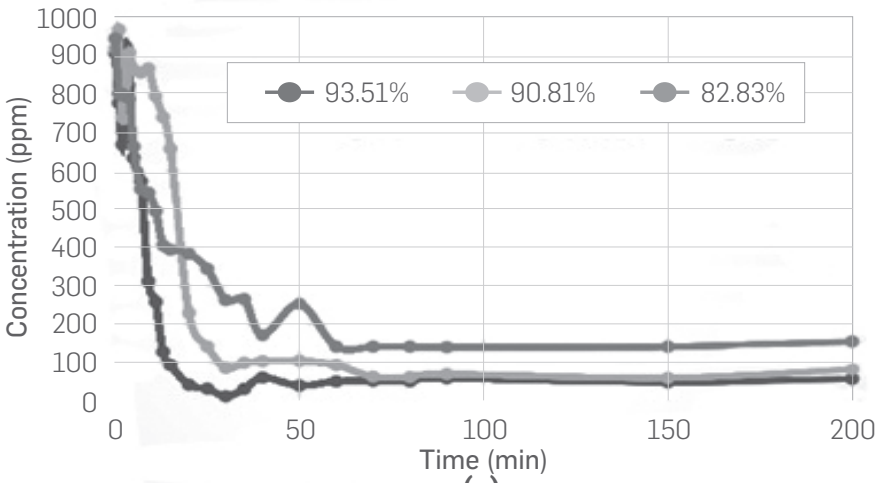

(e)

Figure 1. Hydrocarbon degradation curves in samples (a) MS2, (b) MS4 (c) MS6, (d) MS8, (e) MS10, using a 15 mL reactor. The degradation experiments were performed in triplicate for each initial concentration. 
Table 3 summarizes the percentages of average degradation and the variation coefficients for the different synthetic samples. Apparently, there is no correlation between the initial hydrocarbon concentration and the final degradation percentage.

Table 3. Degradation percentages and variation coefficient obtained from the experimental data corresponding to the degradation curves shown in Figure 1.

\begin{tabular}{|c|c|c|}
\hline Sample & Degradation percentage & Variation coefficient \\
\hline MS2 & $94 \pm 4 \%$ & $1.9 \%$ \\
\hline MS4 & $88 \pm 6 \%$ & $3.0 \%$ \\
\hline MS6 & $75 \pm 11 \%$ & $5.9 \%$ \\
\hline MS8 & $85 \pm 9 \%$ & $4.4 \%$ \\
\hline MS10 & $89 \pm 10 \%$ & $4.7 \%$ \\
\hline
\end{tabular}

- The uncertainties reported were calculated based on statistical t-Student theory, with 95\% confidence level [24]

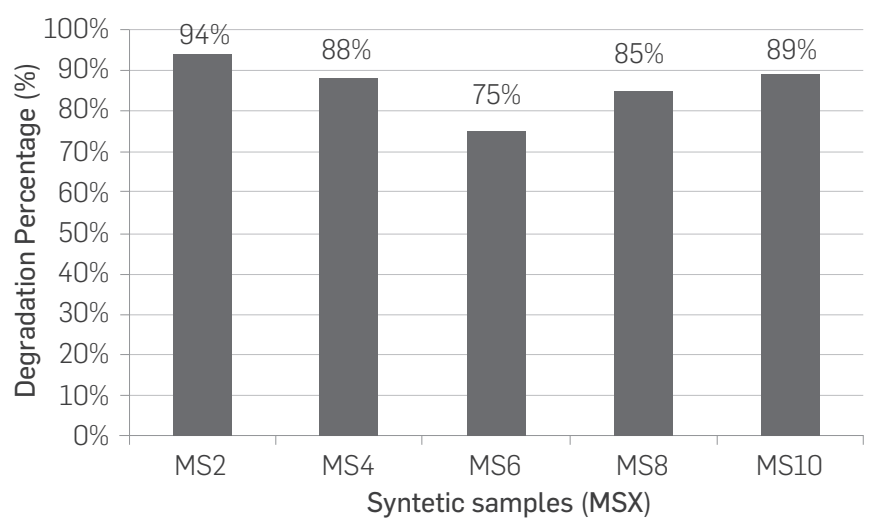

Figure 2. Graphical report of parameters shown in table 3.

Table 4 shows the results of the degradation process of the field sample (MC) obtained from the inflow to a skimmer of a plant located in the eastern plains region of Colombia. The data obtained in degradation experiments are also shown for a 1: 2 dilution of the field sample (MCD) and a concentrated synthetic sample (MSC). The samples were subjected to the degradation process during (210 $\mathrm{min}$ ), in the $1.0 \mathrm{~L}$ capacity photocatalytic reactor. The reported concentrations were obtained using the TPH method (gravimetric partition) by Prodycon S.A.

Table 4. Results of the degradation of hydrocarbons present in a field sample (MC), diluted at : 2 (MCD), and a concentrated synthetic sample (MSC).

\begin{tabular}{|c|c|c|c|}
\hline Sample & Sample & Final concentration & Degradation \% \\
\hline (MC) & $145.9 \pm 0.5 \mathrm{mg} / \mathrm{l}$ & $12.9 \pm 0.5 \mathrm{mg} / \mathrm{l}$ & $91.2 \%$ \\
\hline (MCD) & $78.2 \pm 0.5 \mathrm{mg} / \mathrm{l}$ & $6.2 \pm 0.5 \mathrm{mg} / \mathrm{l}$ & $92 \%$ \\
\hline (MSC) & $32645.2 \pm 0.5 \mathrm{mg} / \mathrm{l}$ & $0.6 \pm 0.5 \mathrm{mg} / \mathrm{l}$ & $99 \%$ \\
\hline
\end{tabular}

The degradation percentages reported in Table 4 confirm that the photocatalytic processes proposed hereunder allow for a high yield in the reduction of hydrocarbon concentration in produced water.

These results open up the possibility of implementing this process at an industrial level, where production water represents is one of the main problems of oil production. By having the possibility of treating large volumes of water with a proportionally low cost method, operating costs would be reduced and this saving would translate into better economic profitability of the drilling and oil production project.

It is also worth pointing out that according to resolution 0631 of 2015 of the Ministry of Environment and Sustainable Development, the maximum permissible limit of TPH in production waters, to be discharged into surface water bodies is $10 \mathrm{mg} / \mathrm{l}$. According to Table 4, the final concentration obtained in the field sample is $2.9 \pm 0.5$ $\mathrm{mg} / \mathrm{l}$ above the standard.

Bearing in mind that this research is a preliminary study on the photocatalytic removal of hydrocarbons with modified $\mathrm{TIO}_{2}$, and the bibliography search carried out, no publications of this technological approach were found in the hydrocarbon industry, the results are promising and open the door to the treatment of this type of effluents nowadays.

Finally, Table 5 shows project costs:

Table 5. Project Costs at Laboratory Scale

\begin{tabular}{|c|c|}
\hline Costs & COP \\
\hline Materials and reagents & $\$ 634000$ \\
\hline Costs associated with laboratory use & $\$ 287000$ \\
\hline Hydrocarbon analysis & $\$ 700000$ \\
\hline Total project at laboratory scale & $\$ 1621000$ \\
\hline
\end{tabular}

It should be noted that the materials and reagents correspond to $39 \%$ of the total cost; as compared with the oil industry, hydrocarbon analysis and measurement techniques are either well known (61\% of the costs of this project), implemented or part of routine activities, and are carried out independently of the treatments used for waste disposal. Even though the adaptation on an industrial scale of the system proposed in this paper depends on specific variables and conditions of the oil sector in particular, the implementation costs would include the same non-dimensional characteristics of the reactor described herein (See experimental session). It is worth highlighting that the the photocatalyst base material (titanium dioxide) is economical and abundant and visible solar radiation can be obtained, without need for installation of lighting circuits. Hence, photocatalysis for the treatment of water in the oil industry is a potentially promising and economic technology.

\section{CONCLUSIONS}

The photocatalytic degradation of hydrocarbons in synthetic and field samples of production waters was studied. Based on the results obtained at lab level, it was concluded that it is feasible to treat production waters to degrade present hydrocarbons, reaching degradation percentages above $91 \%$ and validating the experimental methodology. These results enabled us to conclude that the exposed treatment method is a modern and feasible alternative for the reduction of costs associated with the treatment and its application in the industry.

Photocatalytic degradation is a technique that, in addition to other factors, involves the use of artificial radiation sources to provide the necessary energy and thus enable degradation. By sensitizing of $\mathrm{TiO}_{2}$ with iron oxide (III), these degradations are achieved using radiation in the visible spectrum, allowing for use 
of natural radiation and avoiding additional facilities to obtain the necessary energy. The intent is, therefore, to take advantage of solar radiation in oil fields for subsequent industrial implementation.

Evidence was obtained in this work of the removal capacity through sensitization of $\mathrm{TiO}_{2}$ and guidelines are ready for determining in subsequent studies the increase in efficiency Vs the amount of precursor in the cyclic chemisorption-calcination technique that was used.
Photocatalytic degradation methods have proven to be a real alternative for the treatment of production water by improving its physicochemical conditions, considering their subsequent discharge/ reinjection/disposal. This study makes it possible to propose an alternative treatment method to the oil industry, which must be continually enhanced due to its being constantly challenged by the environmental impacts it generates.

\section{ACKNOWLEDGEMENTS}

To Dr. Sc. Cesar Augusto Quiñones Segura for allowing performance of this project in the Photoactive Materials Research Group of Universidad de América, to Professor M. Sc. Andrés Felipe Loaiza, for providing some of the means and knowledge required for the development of the topics addressed in the project, to laboratories Prodycon S.A. for providing its standardized gravimetric tests service to verify the results presented.

\section{REFERENCES}

[1] Navarro, S. \& Renata B, Fracking Expands in Latin America, Threatening to Contaminate World's ThirdLargest Aquifer, Truth-Out, 2015. [On-line]. Available: http://www truth-outorg/news/item/33910-frackingexpands-in-latin-america-threatening-to-contaminateworld-s-third-largest-aquifer

[2] Alvarez, L. Ecopetrol SA, Cero Vertimientos, 2001 [On-line]: Available: http://www.ecopetrol.com.co/ especiales/carta petrolera125/produccion.htm

[3] Long, J.,Liu, H., Wu, S.,Liao, S. and Li, Y. Selective Oxidation of Saturated Hydrocarbons Using Au-Pd Alloy Nanoparticles Supported on Metal-Organic Frameworks, Catalysis, 2013, 3 (4), 647-654.

[4] Serna, W. J.,Peñuela, G. A. \& López, C. A. Estimación de la incertidumbre en la medición de hidrocarburos aromáticos en el análisis de muestras de agua por microextracción en fase sólida automático y cromatografía de gases con detección selectiva de masas, 2012, 15(8), 37-44. doi:ISSN 1900-2351

[5] Bravo, Elizabeth. Los impactos de la explotación petrolera en ecosistemas tropicales y la biodiversidad, Acción ecológica, 2007, 13

[6] D'Auria, M., Emanuele, L., Racioppi, R. \& Velluzzi, V. Photochemical degradation of crude oil: Comparison between direct irradiation, photocatalysis, and photocatalysis on zeolite. Journal of Hazardous Materials, 2009, 164(1), 32-38.

[7] Ruiz-García, M., Pérez, O. \& Ruiz-Escobar, F. Evaluación de la contaminación por hidrocarburos en la bahía de Mariel, Transporte, desarrollo y medio ambiente, 2007, 27(1), 27.

[8] Alaton I.A., Balcioglu I.A., Bahnemann D.W. Advanced oxidation of a reactive dyebath effluent: comparison of O3, H2O2/ UV-C and TiO2/UV-A processes, Water research, 2002, 36(5), 1143-1154

[9] Legrini O.; Oliveros E.; Braun A.M. Photochemical processes for water treatment, Chemical Review, 1993, 93, 671-698

[10] Gogate P.R.: Pandit A.B. A review of imperative techonologies for wastewater treatment II: hybrid methods, Advances in Environmental Research, 2004. 8(3-4), 553-597
[11] Wu C.H.; Chang C.L.; Kuo C.Y. Decolorization of proción MX-5B in electrocoagulation (EC). UV/TiO2 and ozone related systems, Dyes and Pigments, 2008 76(1), 187-194.

[12] Lucas M.S.; Dias A.A.; Sampaio A.; Amaral C. Peres J.A. Degradation of a textile reactive azo dye by a combined chemicalbiological process: Fenton's reagentyeast, Water research, 2007, 41(5), 1103-1109

[13] Bautista P: Mohedano A.F. Gilarranz M.A.; Casas J.A.: Rodríguez J.J. Aplication of Fenton oxidation to cosmetic wastewaters treatment, Journal of Hazardous Materials, 2007, 143(1-2), 128-134

[14] Parra S.P. Coupling photocatalytic and biological processes as a contribution to the detoxification of water: catalytic and technological aspects, Tesis Doctoral. Thèse no 2470. Présentée au Departement de Génie Rural. École



[15] García-Martínez, M. J., Da Riva, I., Canoira, L., Llamas, J.F., Alcántara, R., \& Gallego, J. L. R.,Photodegradation of polycyclic aromatic hydrocarbons in fossil fuels catalysed by supported TiO2. Applied Catalysis B: Environmental, by supported TiO2, Applied
2006, 67(3-4), 279-289

[16] Garcés Giraldo, L. F., Franco, M., Alejandro, E., \& Santamaría Arango, J J La fotocatálisis como alternativa para el tratamiento de aquas residuales, 2012

[17] Hashimoto, K., Irie, H. \& Fujishima A., TiO2 photocatalysis: A historical overview and future prospects, Japanese Journal of Applied Physics, 2005 44(12), 8269-8285

[18] Agency for toxic substances and disease registry Identity and analysis of total petroleum hydrocarbons, Toxicological profile for total petroleum hydrocarbons (TPH), 1999, USA, 315.

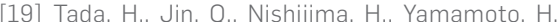
Fujishima, M. Okuoka, S. Hattori, T Sumida, Y \& Kobayashi, H, Titanium(IV) Dioxide Surface-Modified with Kobayashi, H, Titanium(IV) Dioxide Surface-Modified with
Iron Oxide as a Visible Light Photocatalyst, Angewandte Chemie, 2011, 50(15), 3501-3505

[20] Kondo, Y., Suzuki, K., Matsumoto, E., Kobayashi, Y. \& Ishikawa K. Film forming mask and mask adhesion method. IFI CLAIMS Patent Services, W02009075163 A1, Jun. 18, 2009
[21] Rice, W., Baird, B., Eaton, D., Standard Methods for the Examination of Water and Wastewater, 22nd ed., American Public Health Association, 2012, 1495

[22] Álvarez, A., Rueda, B. \& Paternina, R. Validación e implementación de un método analítico para la determinación gravimétrica de hidrocarburos totales en muestras de agua superficial y residual. Memoires of the II South Caribbean Seminar of Environmental Science \& VII International Environmental Management Seminar, Santa Marta, Colombia, Sept 10-12, 2014

[23] US Environmental Protection Agency (EPA), Method 1664, revision A: N-hexane extractable material (hem; oil and grease) and silica gel treated $\mathrm{N}$-hexane extractable material (sgt hem; non-polar material) by extraction and gravimetry, 1999, EPA-821-R-98-002.

[24] Trujillo, C. A. \& Sanchez, J. E., Técnicas y Medidas Básicas en el Laboratorio de Química, Universidad Nacional de Colombia, 2007, 80-83. 